\title{
Clinical psychology: a psychosocial antidote to biological reductivism in psychiatry? The Italian scenario
}

\author{
GIOVANNI A.FAVA
}

In the late 70's, while a student in Italy, I was spending a summer with Professor Lipowski in the Department of Psychiatry of Dartmouth Medical School in Hanover, New Hampshire. Once a week my professor went to New York City, to see his friend Bob (who, I later learned, was Robert Spitzer). They were working on something which would have become the DSM-III (American Psychiatric Association, 1980). Professor Lipowski had a key role in the architecture of the chapter on organic mental disorders. I remember him saying "I am having such a hard time trying to persuade psychiatrists of the importance of the brain, and specifically of diagnosing and treating organic mental disorders. They belong to psychiatry and not to neurology". He then added: What is ironic is that, twenty years from now, we will have trouble preserving the role of the mind in mental disorders". I thought of those words when in the late eighties I read my former teacher's classic paper on the shift from the one-sided emphasis on psychological and social issues (brainless psychiatry) to the opposite trend toward extreme biologism (mindless psychiatry) (Lipowski, 1989).

I am thinking of those words now, while I am writing this editorial addressing the relationship of clinical psychology to psychiatry.

Can clinical psychology be the antidote to "mindless psychiatry", to the current neglect of psychosocial issues, both in terms of assessment and treatment, in mental disorders?

Certainly clinical psychology has this potential. But there is still a long way to go, particularly in European countries such as Italy.

Indirizzo per la corrispondenza: Professor G.A. Fava, Department of Psychology, University of Bologna, Viale Berti Pichat 5, 40127 Bologna.

Fax: +39-051-243.086

E-mail: fava@psibo.unibo.it
In the late 70's, the role of the clinical psychologist in practice was mainly as an expert in psychological testing (particularly the IQ or MMPI and the Rorschach, in case of doubtful diagnostic cases). Abnormal psychology was identified as a research area concerned with the administration of psychological testing to psychiatric patients. Psychotherapy research was its initial phase and was still unclear whether one type of psychotherapy could be regarded as superior to others in specific disorders (Smith et al., 1980). The enthusiasm for the DSM-III, after an initial resistance, pervaded American clinical psychology and, with the due delay, also the European one. Curiously, however, around the world clinical psychologists are still administering MMPI and Rorschach, despite the considerable body of research pointing to their flaws and inadequacies (Gleser, 1974).

May be it is because the DSM has not solved all our problems. At the same time, despite a tremendous progress in psychopharmacology, drug treatment does not seem to be able to favorably affect long term outcome in highly prevalent disturbances, such as mood and anxiety disorders (Piccinelli \& Wilkinson, 1994; Fava \& Mangelli, 1999). In the 70's, the psychotherapy research arena was shared by psychiatrists and psychologists, whereas nowadays it has become a Ph.D. business (Bergin \& Garfield, 1994). The fact is really paradoxical since it comes to a time when specific types of psychotherapy (cognitive-behavioral, interpersonal, etc.) have been found to entail long lasting recovery and to be comparable or superior to other treatments in a number of psychiatric disorders (Bergin \& Garfield, 1994; Sartorius et $a l ., 1993)$. Several current areas of research of clinical psychology may be particularly important in the years to come. The first is concerned with abnormal psychology. There is a growing need of conceptual frameworks which are geared to the subclinical aspects and longitudinal development of mental disorders (Fava, 1999). For instance, in the late eighties our research group tested an old phenomenological observation (panic attacks occur- 
ring "not out of a clear sky") with the methods of abnormal psychology (a specific hypothesis explored with well validated psychometric methods): subclinical agoraphobia and hypochondriasis were found to precede panic attacks in the majority of cases (Fava et al., 1988). Despite initial skepticism by the psychiatric establishment, later research - reviewed in details elsewhere (Fava \& Mangelli, 1999) - has confirmed those findings. Specific hypotheses leading to a selective use of psychometric instruments below syndrome intensity and across diagnostic boundaries, which characterize abnormal psychology, may unravel important clinical insights in the assessment of mental disorders. On the contrary, too frequently psychiatric research takes a "blanket approach": several psychological instruments are used, often highly redundant in nature, under the misguided assumption that "nothing will be missed" with such discriminative strategy. This approach only confounds the issue and violates the psychometric principle of incremental validity: the incremental increase in predictive power associated with the inclusion of a particular assessment procedure in the clinical decision process (Derogatis, 1987). Each distinct aspects of psychological measurement should deliver a unique incremental increase in information in order to qualify for inclusion.

A second important line of development concerns psychotherapy research. Not only brief psychotherapeutic strategies (particularly cognitive-behavioral) have become an evidence-based first line treatment of various mental disorders (Bergin \& Garfield, 1994; Sartorius et al., 1993). The past two decades have witnessed an unprecedented refinement of their technical components and new exciting developments and changes in paradigms are on the way (Marks, 1999; Fava, 2000). An example is provided by the role of cognitive behavioral therapy in relapse prevention of recurrent depression (Fava et al., 1998; Paykel et al., 1999; Jarrett et al., 2000). While psychotherapy yields enduring effects, drug treatment cannot provide protection after its discontinuation, i.e. duration of treatment is irrelevant (whether 3 months or 3 years), when the antidepressant is stopped (Viguera $e t$ al., 1998). Psychiatrists may soon come to realize that a higher effectiveness does not rest on pharmacological grounds (SSRI can be prescribed by any primary care physician with equivalent results), but in their non-pharmacological skills.

A final promising dimension of clinical psychology involves psychological well-being and can be subsumed under the rubrics of positive psychology, health psychology and well-being therapies (Ryff \& Singer, 2000). Ryff \& Singer (2000) remark that, historically, mental health research is dramatically weighted on the side of psychological dysfunction and that health is equated with the absence of illness rather than the presence of wellness. They suggest that the absence of well-being creates conditions of vulnerability to possible future adversities and that the route to recovery lies not exclusively in alleviating the negative, but in engendering the positive. Novel, well-being oriented psychotherapeutic approaches, such as well-being therapy (Fava, 2000) have been developed and are likely to play a major role in the years to come.

The promising horizons available are, however, in contrast with the current state of clinical psychology in many countries.

There are no data on the exact number of clinical psychologists working in Italy. Only a very small proportion operates within the National Health System in settings such as mental health teams. Psychology courses extend over 5 years and may confer the title of clinical psychologist. This system is going to change next year and have an Anglo-Saxon structure: the first 3 years may confer a bachelor degree in psychological science, whereas 2 additional years may provide a master degree in various psychological specialties, including clinical psychology. The Italian Psychological Association has a special section concerned with licensed psychotherapists. Only those who complete a 4 year postgraduate training in psychotherapy may be enrolled. Training may take place in academic settings (but the number of available positions is quite insufficient) or in private institutions which have obtained appropriate recognition. The orientation of these private schools is very differentiated: from behavioral to psychodynamic, from family to client-centered therapy. The general orientation of Italian clinical psychologists is, however, psychodynamic and reflects that of academic clinical psychologists. In the past decade there has been a considerable growth of cognitive behavioral therapies. The systemic approach, which has a long tradition (the Milano school) is also exerting a considerable influence.

Academic research in Italian clinical psychology is insufficient, despite the presence of strong research groups (Bignami et al., 2000). Most of the clinical psychologists do not perform research at an international level (Fava \& Montanari, 1998). There are several Italian journals of psychology, including a long-established journal concerned with psychological testing (Bollettino di Psicologia Applicata) and a more recent journal on cognitive behavioral therapy (Psicoterapia Cognitiva e Comportamentale), which share the limitations of all non-English speaking journals. Italian clinical 
psychology has not endorsed yet an evidence-based approach to modalities of assessment and treatment, whereas this is gaining wide currency in Italian clinical medicine. Its situation is thus particularly indicative of a more general European trend. Clinical psychology may have an increasingly important role in the assessment and treatment of mental disorders, both as a dimension of psychiatric practice which is a requirement for physicians (with the ensuing educational implications) and a professional discipline which subsumes the clinical contribution of psychologists. Its growth will depend on its rate of renewal and readiness to meet the biopsychosocial challenges of the new millenium.

Acknowledgements. I am grateful to Professor Adolfo Pazzagli (University of Florence), who provided valuable criticism and comments.

\section{REFERENCES}

American Psychiatric Association (1980). Diagnostic and Statistical Manual of Mental Disorders (DSM III) (3rd ed.). American Psychiatric Association: Washington DC.

Bergin A.E. \& Garfield S.L. (1994). Handbook of Psychotherapy and Behavior Change. Wiley: New York.

Bignami G., de Girolamo G., Fava G.A., Gaston A., Morosini P.L., Pastore V. \& Tansella M. (2000). L'impatto sulla letteratura internazionale della produzione scientifica dei ricercatori italiani, nelle discipline "psichiatria" e "psicologia". Una valutazione bibliometrica. Epidemiologia e Psichiatria Sociale 9, 11-25.

Derogatis L.R. (1987). The Derogatis Stress Profile (DSP): quantification of psychological stress. In Research Paradigms in Psychosomatic Medicine (ed. G.A. Fava and T.N. Wise), pp.30-54. Karger: Basel.

Fava G.A. (1999). Subclinical symptoms in mood disorders. Psychological Medicine 29, 47-61.
Fava G.A. (2000). Cognitive behavioral therapy. In Encyclopedia of Stress, Vol 1 (ed. M. Fink), pp. 484-497. Academic Press: San Diego, Ca.

Fava G.A. \& Mangelli L. (1999). Subclinical symptoms of panic disorder. Psychotherapy and Psychosomatics 68, 281-289.

Fava G.A. \& Montanari A. (1998). National trends of research in behavioral sciences (1981-1996). Psychotherapy and Psychosomatics 67, 281-301.

Fava G.A, Grandi S. \& Canestrari R. (1988). Prodromal symptoms in panic disorder with agoraphobia. American Journal of Psychiatry 145, 1564-1567.

Fava G.A., Rafanelli C., Grandi S., Conti S. \& Belluardo P. (1998). Prevention of recurrent depression with cognitive behavioral therapy. Archives of General Psychiatry 55, 816-820.

Gleser G.C. (1974). Evaluation of psychotherapy outcome by psychological tests. In Psychotherapy Change Measures (ed. I.E. Waskow \& M.B. Parloff), pp.32-39. DHEW Publications: Washington.

Jarrett R.B., Kraft D., Schaffer M., Witt-Browder A., Risser R., Atkins D.H. \& Doyle J. (2000). Reducing relapse in depressed patients with atypical features. Psychotherapy and Psychosomatics 69, 232 239.

Lipowski Z.J. (1989). Psychiatry:mindless or brainless, both or neither? Canadian Journal of Psychiatry 34, 249-254.

Marks I. (1999). Is a paradigm shift occurring in brief psychological treatments? Psychotherapy and Psychosomatics 68, 169-170.

Paykel E.S., Scott J., Teasdale J.D., Johnson A.L., Garland A., Moore R., Jeneway A., Cornwall P.C., Hayhurst H., Abbott R. \& Pope M. (1999). Prevention of relapse in residual depression by cognitive therapy. Archives of General Psychiatry 56, 829-835.

Piccinelli M. \& Wilkinson G. (1994). Outcome of depression in psychiatric settings. British Journal of Psychiatry 164, 297-304.

Ryff C.D. \& Singer B.G. (2000). Biopsychosocial challenges of the new millenium. Psychotherapy and Psychosomatics 69, 170-177.

Sartorius N., de Girolamo G., Andrews G., German G.A. \& Eisenberg L. (1993). Treatment of Mental Disorders. World Health Organization: Washington, DC.

Smith M.L., Glass G.V. \& Miller T.I (1980). The Benefits of Psychotherapy. John Hopkins University Press: Baltimore.

Viguera A.C., Baldessarini R.J. \& Friedberg J. (1998). Discontinuing antidepressant treatment in major depression. Harvard Reviews of Psychiatry 5, 293-306. 